\title{
La ciudad romana de Singilia Barba. La materialización de una herencia
}

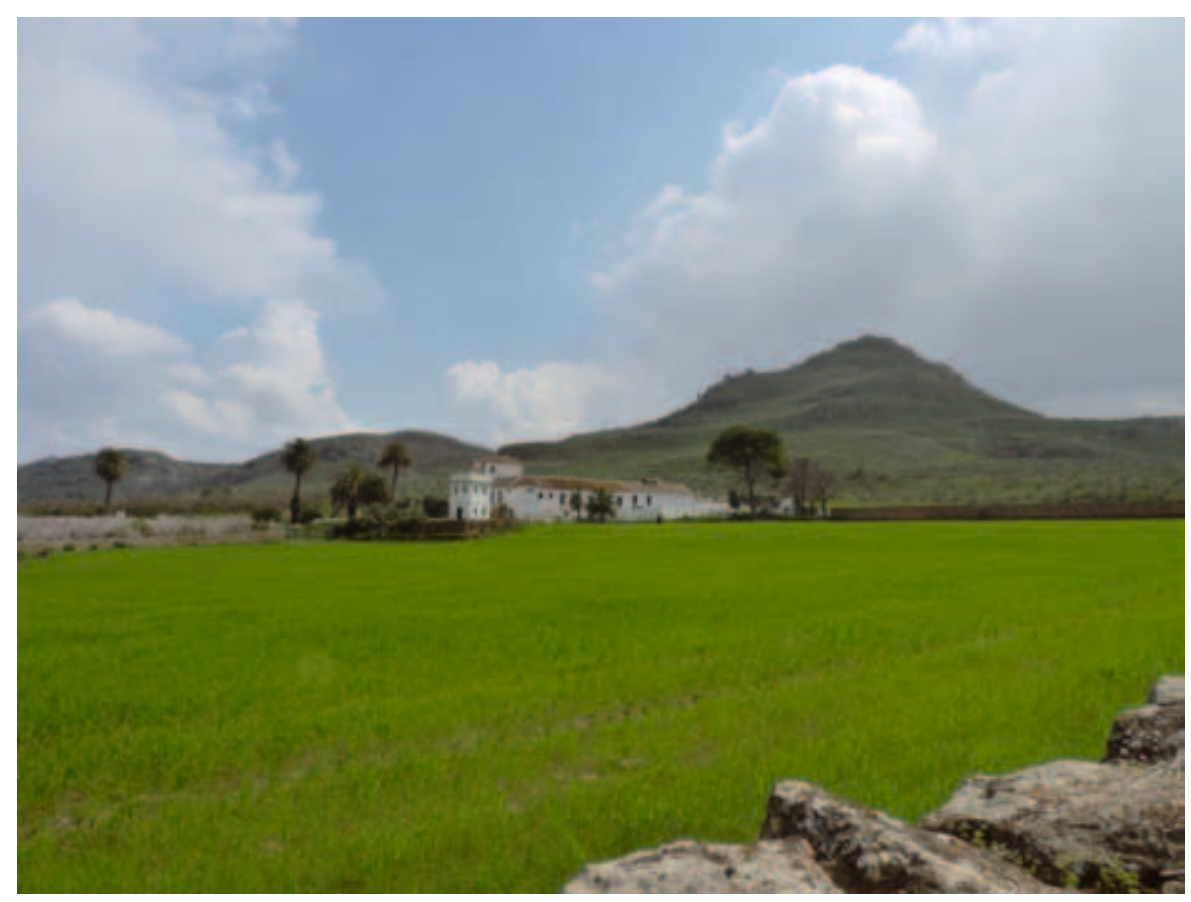

Cortijo y cerro del Castillón al fondo. Foto: Juan B. Fernández Luque, 2010

Hasta no hace muchos años, cuando el viajero ascendia el Puerto de las Pedrizas y su mirada caía sobre la vega de Antequera, al viso de la Cuesta de El Romeral, podía observar un hermoso paisaje agrario de tonos verdes y ocres, tachonado de blancas cortijadas, en cuyos patios y exteriores se elevaban las oscuras manchas de los cipreses. Este árbol, tan asociado en nuestra mente a las recreaciones de las villae romanas, también jalonaba los caminos, de modo que la vista general evocaba en el espectador paisajes de otros tiempos más remotos que hoy hemos sacrificado en busca de la modernidad. En este corazón viario de Andalucía, en un paisaje no muy distinto al descrito, se fundó la ciudad romana de Singilia Barba, abalconada sobre el territorio que la circunda.

Pero, ¿cómo explicarnos la configuración de un paisaje antiguo, del que además los antequeranos modernos somos deudores? Al igual que nosotros recurrimos al análisis del pasado, profundizando en las aportaciones históricas que proporciona la Singilia romana para tener una noción más clara de nuestro presente, asi deberemos profundizar en la historia de la ciudad romana, al objeto de comprender mejor su implantación sobre el paisaje.

La vega de Antequera es desde la Prehistoria una de las comarcas naturales andaluzas más frecuentadas por el hombre. No obstante, la humanización del paisaje no se vio acelerada hasta las fases recientes del Neolítico y, fundamentalmente, a lo largo del Calcolitico. Primero, grupos itinerantes recorrieron estacionalmente sus parajes más aptos. Con el correr del tiempo, las bonanzas climáticas y el potencial económico de la llanura y los piedemontes que la circundan favorecieron la evolución de las estructuras sociales y la consolidación de hábitats estables en aquellos puntos que reunían mejores condiciones para el control del territorio. De una constelación de pequeños asentamientos neolíticos, surge en el Cerro del Castillón un poblado calcolitico, cuya continuidad durante las diversas etapas de la Edad del Bronce serán el germen de un potente oppidum ibérico que posibilitará, con la llegada de los romanos, la fundación de Singilia (ATENCIA PÁEZ, 1988: 42).

Sobre el origen de la ciudad como tal, hoy sabemos que se adaptaron y reforzaron las antiguas murallas pertenecientes al oppidum ibérico con una carga de simbolismo que supera su utilidad poliorcética real.

No obstante, y en virtud de los datos relativamente abundantes proporcionados por la arqueologia antequerana, debemos proponer ciertos matices en cuanto a los fenómenos que se enmascaran tras la romanización de la zona. Tradicionalmente

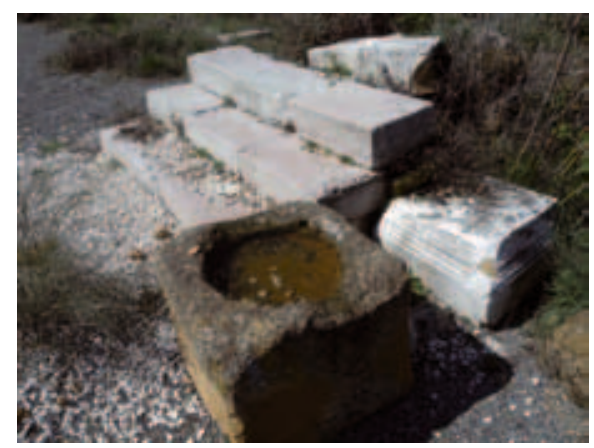

Foro de Singilia, escalinata de marmora del torcal que daba acceso a uno de los pequeños templos. Foto: J. A. Suárez, 2010 se ha considerado que la asunción de los nuevos parámetros llegados con la romanización se produjo con prontitud en el ámbito de la Baetica; sin embargo, este modelo interpretativo parece cuestionarse en el caso del territorio antequerano. Se impone una clarificación de datos que de manera objetiva corrija aquellos tópicos tradicionalmente acomodados en la historiografía sobre esta temáti$c a$, ofreciendo nuevos elementos de juicio para una veraz interpretación. Lo cierto es que, a partir de los trabajos arqueológicos más recientes, sabemos que el entramado de villas dependientes de Singilia no se construye con anterioridad al cambio de Era. Los restos materiales de cronología más temprana pueden ser considerados como elementos residuales en sus registros, asociados con precisión a depósitos erosivos y alterados, o bien insertos en sus cimentaciones, que en modo alguno pueden vincularse a sus fundaciones, sino más bien parecen relacionarse con evidencias de pequeñas explotaciones agropecuarias de tradición indigena con escasos programas edilicios. Será a partir de la época Flavia, en la segunda mitad del siglo I d. C., cuando se produce la ocupación intensiva del territorio, en especial del ager anticariense y singiliense. No es casual que Anticaria obtenga su estatuto de municipalidad, probablemente latina; con el emperador Galba y Singilia se constituya en municipio latino con el singular título de municipium flavium liberum singiliense, conservando en esta titulatura la referencia evidente a su antiguo estatus de ciudad libre.

En cualquier caso, como podemos observar, la llegada de los romanos al enclave no supuso una novedad en lo que se refiere al poblamiento. Las evidencias arqueológicas revelan que el gran monte de aspecto piramidal que domina la ciudad alojó desde el siglo $V$ antes de la era un importante núcleo de población ibérica, asentado precisamente sobre la elevación mejor protegida, dominando por su altimetría el extremo occidental de la vega. La ciudadela ibérica, configurada como un auténtico oppidum aterrazado, ocupó las cotas altas del Castillón, como atestigua el potente lienzo de muralla que aún altera el perfil natural de la ladera. Con la fundación de la ciudad romana, a sus pies y en la falda del mismo, podemos suponer que la población indigena quedaria rápidamente asimilada entre los contingentes plenamente romanizados.

La misma estructura de ciudad aterrazada parece mostrar también la Singilia romana; las excavaciones sistemáticas realizadas hasta la fecha se centraron sobre un espacio forense situado en una de las terrazas de la ladera media. Estos trabajos permitieron excavar varios templos de reducidas dimensiones, del tipo aedicula, así como un espacio despejado finamente enlosado con grandes lastras pétreas que daba acceso a un recinto basilical revestido de marmora locales, mostrando sitiales del mismo material que recorren su perimetro interno, apoyados sobre remates con forma de garra de felino (SERRANO RAMOS et ál., 1991: 277). En la terraza inmediatamente inferior, se encuentra otro de 


\section{Podemos suponer que \\ la visión desde la propia ciudad hacia su ager circundante debía ser una clara expresión de la feracidad de su agro. Seguramente no muy distinto al que podemos \\ contemplar hoy}

fundidad, en espera de que la Arqueología desvele sus misterios.

En la terraza baja, conectando con el plano aluvial que da paso a la margen izquierda del río Guadalhorce, el análisis de las fotografias aéreas y los hallazgos epigráficos han permitido descubrir la presencia de un circo de notables dimensiones. El posterior reconocimiento del terreno nos invita a pensar en su excepcional estado de conservación. Vemos cómo los grandes edificios públicos del municipio romano se estructuraron de forma escalonada a favor de la pendiente del Cerro del Castillón, distribuyéndose las residencias urbanas, domus, tanto al pie del mismo como en sus vertientes; sólo tres de ellas se han documentado parcialmente hasta la fecha (SERRANO RAMOS et ál., 1991: 275).

La necrópolis principal estuvo situada en la vertiente occidental y flanqueando la calzada que daba acceso a la ciudad desde el oeste tras cruzar el actual

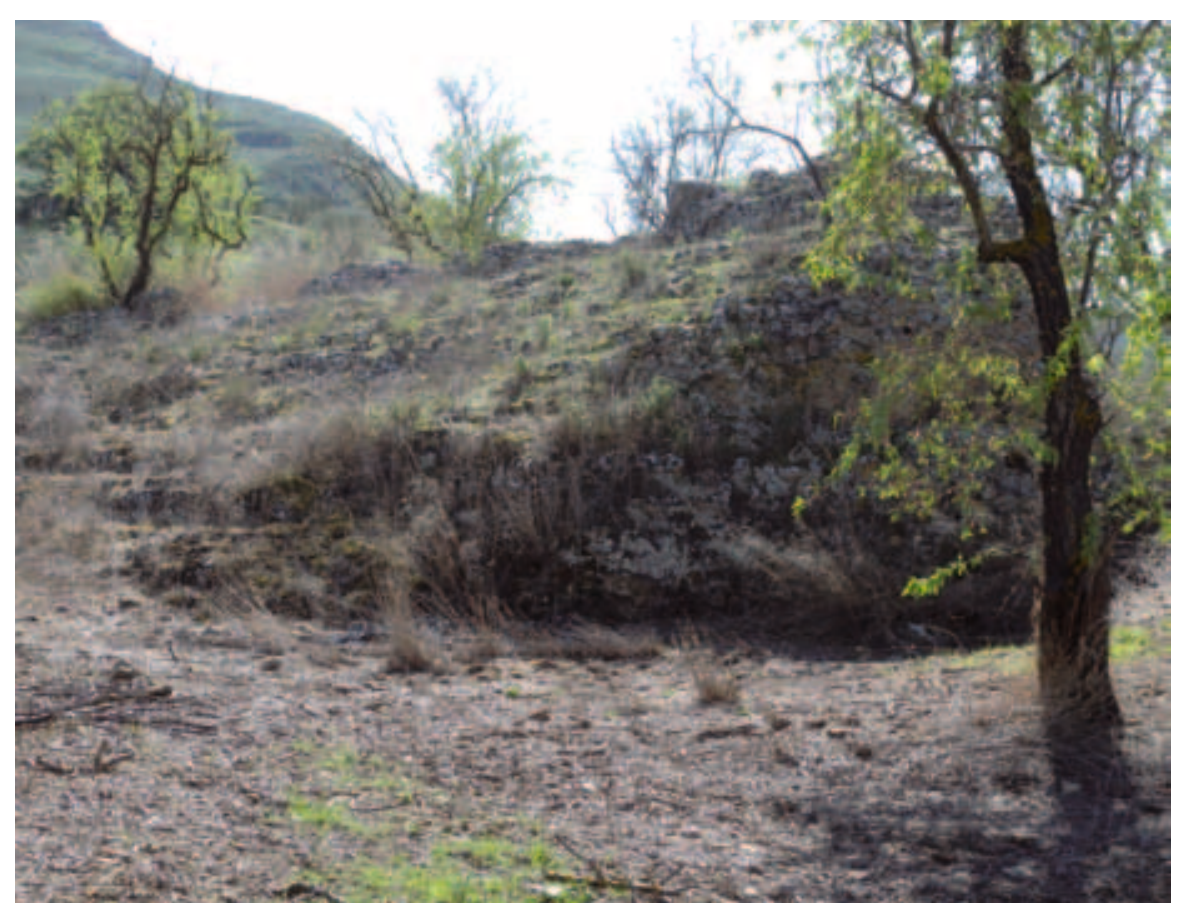

Vista del extremo oeste de la summa cavea del teatro romano de Singilia Barba. Foto: J. A. Suárez, 2010

los edificios paradigmáticos de las ciudades romanas, el teatro. Aún sin excavar, su conocimiento se remonta al siglo XVI, según trasmiten los cronistas de la época. Un siglo después, parte de sus sillares fue desgajados del graderío alto y reutilizados en la construcción de la iglesia antequerana de San Juan de Dios (ATENCIA PÁEZ, 1988: 54). Los grabados de la época así lo atestiguan. Recientemente se han acometido exploraciones geofísicas con modernas técnicas de RADAR de suelo que revelan que sus estructuras, hoy tapizadas por los derrubios coluviales de ladera, yacen en buen estado a 15 metros de pro- arroyo de Valsequillo. Se conocen varios mausoleos monumentales de tipo columbario, elaborados con bóvedas de sillería (FERNÁNDEZ RODRÍGUEZ; ROMERO RÉREZ, 2007: 18).

Podemos suponer que la vista de la ciudad romana, con sus grandes edificios públicos ricamente ornamentados e implantados en los resaltes naturales del Castillón, rodeados por los viales urbanos y el caserío de la ciudad, debía mostrarse al viajero de la Antigüedad como un marco escénico ciertamente espectacular e impactante. No obstante podemos suponer que la visión desde la propia ciudad hacia su ager circundante debía ser una clara expresión de la feracidad de su agro. Seguramente no muy distinto al que podemos contemplar hoy, con amplias extensiones de cereal y en virtud de la cincuentena de villas rústicas descubiertas en la comarca dedicadas a la producción de aceite, pobladas por densos manchones de olivar (ROMERO PÉREZ, 1998: 139).

No sólo la ciudad trasmite noción de riqueza con sus magnificas construcciones públicas, también su entorno se pobló de establecimientos rústicos y grandes villae, algunas como la de Bobadilla, verdaderos vicus con orientaciones tan diversificadas que no se limitaban a la explotación agropecuaria de sus tierras, sino que incluian producción de vasos cerámicos de consumo y almacenaje, asi como materiales constructivos ejecutados en los barros locales, transformación de menas minerales metálicas $y$, evidentemente, incluian áreas domésticas y de recreo, así como grandes ámbitos funerarios situados en torno a los principales caminos. De buena cuenta de ello dio la excavación de la necrópolis de la Villa de las Maravillas, cercana al curso del río e interpretada como residencia de recreo de uno de los personajes singilienses mejor conocidos, Acilia Plecusa, antigua esclava y liberta que casó con un miembro del orden ecuestre, M. Acilio Fronton, quien ostentó el cargo de praefectus fabrum. De su relación directa con la citada villa, sabemos gracias a la excavación de su impresionante mausoleo, planteado en su concepción primigenia como un gran columbario de sillares para recibir urnas de incineración que, por mor de los cambios en las "modas" de los rituales funerarios, terminó acogiendo los restos mortales de Acilia, inhumados en un sarcófago monolítico (ROMERO PÉREZ, 1994: 219).

Podemos concluir que los límites del territorio singiliense vienen dados por el conocimiento, tanto de la alineación de los ejes que orientan la planificación urbana y que, siguiendo las pautas romanas, se perpetúan en su ager de influencia, trazados con rumbo suroeste-noreste, como del punto de captación de aprovisionamiento de aguas para la ciudad, fijado en el Arroyo del Alcázar, desde donde se han descubierto algo más de seis kilómetros del acueducto que servía a Singilia y que, ya en el siglo XVII, el Padre Cabrera describía cuando explicaba las fórmulas de llenado de la naumaquia: "...y el agua que entrava enella setraia de el arroyo de el Alcazar por donde oy esta la pressa y Xavoneria donde se Juntava el agua que oy biene a Antequera, y se traia encañada por arcaduces de Piedra y argamassa por las Laderas de los olibares del partido que dizen de Sotomando hasta entrar en la Laguna..." (sic). Quedando así fijados los límites territoriales, Anticaria al este y Singilia al oeste (ROMERO PÉREZ, 2010).

Manuel Romero Pérez, Oficina Municipal de Patrimonio Histórico, Ayto. de Antequera

Luis Efrén Fernández, Teatro Romano de Málaga,

Consejería de Cultura de la Junta de Andalucia 